\title{
UNA ADAPTACIÓN DE UN MITO GNÓSTICO CON INTENCIÓN FORMATIVA EN LA ANTIGÜEDAD TARDÍA: LOS DEMONIOS DEL CAPÍTULO 65 DE LA VITA ANTONII DE ATANASIO DE ALEJANDRÍA
}

An adaptation of a Gnostic myth with formative intention in Late Antiquity: the demons of Chapter 65 of the Vita Antonii by Athanasius of Alexandria

\author{
F. J. FuerTes \\ Becario FPU, Universidad de Cantabria \\ fjfuertes.spain@gmail.com \\ E-mail: fuertesfj@unican.es
}

Fecha de recepción: 22-II-2011

Fecha de aceptación: 15-III-2011

RESUMEN: Buscando profundizar en la demonología cristiana tardoantigua, el trabajo analiza un ambiguo pasaje de la Vita Antonii de Atanasio de Alejandría donde se narra la ascensión del alma de Antonio a los cielos y su encuentro con unos seres "terribles". El autor parte de los trabajos de J. Daniélou sobre las potencias aéreas y su papel en las distintas variantes del mito gnóstico del ascenso del alma a través de los diferentes cielos. A partir de ahí, el autor profundiza en el análisis del pasaje, aportando diversos paralelos textuales. Termina adhiriéndose a las perspectivas de D. Brakke sobre las teorías ascéticas de Atanasio para defender finalmente que dichos "seres" podrían identificarse con los «arcontes», término de connotaciones heterodoxas que el obispo habría silenciado en sus esfuerzos para inculcar en los fieles la idea de que lo realmente necesario para alcanzar la salvación era un comportamiento moral virtuoso.

Palabras clave: gnosticismo cristiano, monacato, demonios, Atanasio de Alejandría, Vita Antonii.

Abstract: The aim of this work is to deepen into Late Antique Christian demonology, and to analyze an ambiguous passage in the Vita Antonii by Athanasius of Alexandria that describes the ascension of Antonius' soul to heavens and its encounter with such terrible "beings". The author departs from J. Daniélou's works on air powers and its role in some variants of the Gnostic myth about the ascent of the soul through the different heavens. Thereupon, he delves into the passage providing different textual parallels. He finishes joining D. Brakkes' perspectives on Athanasius ascetic theories to 
defend that these "beings" might be identified with the Gnostic Archons, term silenced by the bishop due to its heretical links in his efforts to inculcate the believers with the idea of that the only requirement to achieve salvation was a virtuous moral behavior.

Key words: Christian Gnosticism, monasticism, demons, Athanasius of Alexandria, Vita Antonii.

\section{UnA Visión de ANTONio RodeAda de SILENCIOS*.}

La Vida de Antonio (Vita Antonii) es uno de los textos cristianos más populares de todos los tiempos. Desde su composición por el obispo Atanasio de Alejandría en el 357 d. C., la obra ejerció una influencia enorme y se convirtió en texto indispensable para la formación de todo monje que se preciara durante la Antigüedad Tardía y la Edad Media․ Su legado alcanzó incluso la Edad Moderna, donde sus párrafos inspiraron numerosas pinturas renacentistas y el propio Erasmo de Rotterdam la utilizó en el s. XVI para la construcción de la imagen mítica del caballero cristiano de la Devotio moderna, como puede verse en su Enchiridion ${ }^{2}$.

Como es sabido, la Vita Antonii ( $V A$ ) narra la historia de Antonio, joven egipcio en quien la tradición cristiana personifica el comienzo de la vida monástica. El muchacho, muertos sus padres, recibe una revelación espiritual que le lleva a dejar atrás su vida anterior. Confía a su hermana pequeña a una comunidad de vírgenes $y$, tras repartir entre los pobres el dinero que ha obtenido por la venta de todos sus bienes, renuncia al mundo y se adentra en el desierto. Comienzan así una serie de sucesivos retiros a lo largo de los años en los que el monje va alejándose progresivamente

* Este trabajo ha sido realizado dentro del marco del Proyecto HAR2010-15957 del Ministerio de Educación español y del Programa de Becas FPU de esta misma institución. 1 Según Ponticiano, amigo de San Agustín, la sola lectura de la $V A$ ya despertaba entre sus contemporáneos deseos de abrazar la vida monástica (cf. AGUSTÍN DE HIPONA, Confessiones, VIII, 14-15[ed. CUSTODIO VEGA, A.: Las Confesiones, Madrid, BAC,1968]). La obra servirá de modelo para el resto de vitae monásticas cristianas posteriores. Desde la Vita Ambrosii, se la considera uno de los tres modelos de la biografía cristiana, junto con la Vita Martini y la Vita Pauli. Paladio tendrá al texto de Atanasio muy presente en su Historia Lausiaca, también hay referencias y préstamos en las distintas vidas de Pacomio, la Vida de Hipacio de Calínico, la Vida de Santa Sinclética y en numerosos pasajes de las Historias monásticas del desierto de Judea de Cirilo de Escitópolis, así como en otras muchas fuentes (cf. BARTELINK, G. J. M.: Athanase d'Alexandrie. Vie d'Antoine. Introduction, texte critique, traduction, notes et index par G. J. m. Bartelink, Paris, Sources Chrètiennes (400), 1994, pp. 6869). He utilizado esta edición para el texto griego y la edición de Mohrmann para la versión latina anónima (MOHRMANN, Ch.: Vite dei Santi. Vita di Antonio. Testo critico e commento a cura di G. J. M. Bartelink, Verona, Fondazione Lorenzo Valla, 1974).

2 Cf. SÁNCHEZ LORA, J. L.: «Demonios y Santos: el combate singulan», en TAUTSIET, M. y AMELANG, J. (eds.): El Diablo en la Edad Moderna, Madrid, Marcial Pons, 2004, pp. 166-167. 
de la civilización, al tiempo que progresa en su desarrollo ascético, hasta acabar convertido en un anciano espiritual rodeado de discípulos deseosos de imitarlo y una fuente de inspiración para que muchos otros abracen la vida monástica. Esta es precisamente una de las características más destacables de la Vita Antonii: su fuerte vocación formativa. En el prólogo de la obra, Atanasio desvela que compuso el texto a petición de unos ascetas occidentales que le habían pedido que les relatara las gestas y costumbres de Antonio para poder seguir su virtuoso ejemplo 3 . De hecho, el obispo incluye en su narración varios discursos de Antonio a sus discípulos, repletos de consejos y recomendaciones que hacen de la obra un verdadero manual ascético y un tratado moral, dirigido a los monjes en particular y a todos los fieles cristianos en general.

La VA también contiene numerosas anécdotas y varias visiones de Antonio que complementan los discursos doctrinales y sirven a Atanasio para ilustrar lo afirmado en ellos. El capítulo 65 incluye una de estas visiones, cuya narración constituye uno de los pasajes más ambiguos de toda la obra, en el que el obispo parece estar describiendo una suerte de ascensión del alma del monje a los cielos:

«En cierta ocasión, cuando iba a comer, [Antonio] se levantó para orar y sintió que su mente era arrebatada. Y lo que era más admirable, estando de pie, se veía a sí mismo fuera de síy como llevado a través del aire por algunos seres. Y veía en el aire a otros seres amargos y terribles que querian impedirle pasar. Los que lo conducian se oponian a éstos, que preguntaban si no era culpable. Como querían hacerle rendir cuentas desde su nacimiento, los que lo conducian se opusieron diciéndoles: «El Señor le ha perdonado todo lo cometido desde su nacimiento. [Sólo] es lícito pedirle cuentas por todo lo cometido desde que se hizo monje y se consagró a Dios». Entonces, ya que aquellos acusaban sin pruebas, el camino quedó para él libre y sin obstáculo. Entonces se vio de repente en pie y volviendo a si mismo, y de nuevo era un Antonio completo» (VA 65: 2-5).

Evidentemente, Atanasio emplea en su descripción un lenguaje muy vago que mantiene todo el pasaje en el ámbito de lo impreciso. En primer lugar, ni siquiera está claro cómo se produce la visión de Antonio, si es en realidad algo que el asceta contempla en su mente o se trata de una suerte de viaje extático en el que su alma remonta los cielos ${ }^{4}$.

\section{Cf. VA Pr. 1-4.}

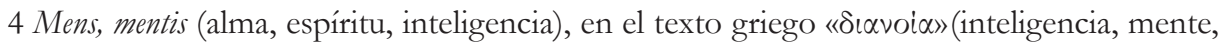
conocimiento), debe entenderse en el episodio en su acepción de alma (cf. VA 65: 2). Atanasio evita pronunciarse acerca de cómo se produce la visión y, cuando glosa el episodio, lo justifica invocando el ejemplo del apóstol Pablo, quien vivió una experiencia similar, que tampoco podía detallar con precisión (cf. VA 65: 9 con los titubeos de Pablo a la hora de describir cómo se produjo la revelación que recibió de Dios: «Sé de un hombre en Cristo, 
Por otra parte, el texto tampoco identifica a ninguno de los "seres" que intervienen en el episodio 5 . En el capítulo siguiente de la obra, Antonio tiene otra visión en la que contempla un solitario gigante deforme que trata de impedir el ascenso de las almas al cielo, pero allí sí se le identifica específicamente como Satán ${ }^{6}$. Pero entonces, qué está ocurriendo realmente en este relato, quiénes son esos «seres terribles» de los que habla el texto y por qué Atanasio emplea un lenguaje tan resbaladizo. Para entender el pasaje e intentar responder a estas preguntas hay que analizar el trasfondo mítico del mismo, en el que se aglutinan — en clave gnóstica — una serie de creencias míticas helenísticas, judías y cristianas, así como la intención del autor al escribir el texto, como vamos a hacer a continuación.

\section{El Mito GNÓSTiCo SOBRE LA ASCENSIÓN DEL ALMA Y SUS PELIGROS}

Fue J. Daniélou el primero en ocuparse de estos «demonios del aire» de la $V A$ en un interesante artículo en el que concluía que, en la teología de Atanasio, el tema del combate espiritual contra los demonios del aire que se oponen a la ascensión del alma era resultado de una convergencia en su espiritualidad de distintas tradiciones religiosas. Por un lado habría concepciones greco-semíticas acerca del aire como lugar de habitación de potencias espirituales y, por otro, la noción específicamente cristiana de los ángeles caídos, precipitados al aire desde el Paraíso a causa de su rebelión contra Dios7. Aunque Daniélou no llegaba a una identificación precisa de esas potencias malignas del aire y abogaba por considerarlas una «turba» ${ }^{8}$, su sólida argumentación puso de manifiesto que la descripción de la ascensión del alma contenida en la visión de Antonio había de explicarse dentro de la tradición del gnosticismo cristiano?.

el cual hace catorce años-si en el cuerpo o fuera del cuerpo no lo sé, Dios lo sabe-fue arrebatado hasta el tercer cielo» (II Cor 12: 2).

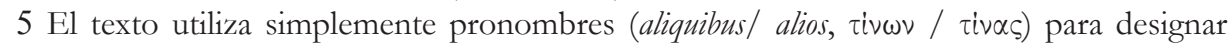
a unas y otras potencias, añadiendo los adjetivos «amargos y terribles» (amaros et pessimos,

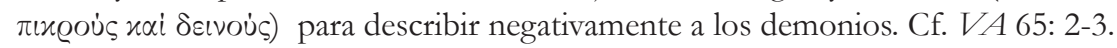

6 Cf. VA 66: 1-4, donde la Providencia revela a Antonio que está contemplando al Enemigo

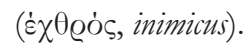

7 Cf. DANIÉLOU, J.: «Les démons de l'air dans la "Vie d'Antoine"》, Studia Anselmiana, 38, (1956), p. 147 (en adelante: DANIÉLOU, J.: «Les démons de l’air...).

$8 \mathrm{El}$ autor remarcaba específicamente la expresión de «l'esprit nombreux de l'ain» de la Homilía Pascual de Hipólito de Roma, que le recordaba a "la foule » des démons de l'air de la Vie d' Antoine ». Ibidem nota anterior, p. 145.

9 No se puede entrar aquí a explicar en profundidad lo que fue el Gnosticismo. Brevemente, el término se acuñó en el s. XVIII d. C. para englobar a un heterogéneo movimiento que tuvo lugar desde el s. I d. C. hasta por lo menos el IV. Lo formaron un conjunto de elitistas grupos religiosos con diversos sistemas de pensamiento pero que mantenían entre sí cierta coherencia. De forma común creían en la existencia en el hombre de una chispa divina que debía regresar a su lugar de origen celeste, aunque para ello tenía que ser despertada por la 
En el Gnosticismo la salvación estaba reservada a una minoría poseedora de un conocimiento superior o gnôsis ${ }^{10}$. Se la concebía como un regreso del alma a la esfera de lo divino, a la que realmente pertenecía. Esta era una creencia común a casi todas las corrientes gnósticas. Un elemento cardinal de esta doctrina es precisamente la idea del ascenso del alma o psicanodia (del griego psyché, "alma" y hódos, "camino")"1. Ese retorno había sido posibilitado por la intervención de un Salvador mítico (identificado con Cristo en la gnosis cristiana) quien, tras descender al mundo bajo revestimiento humano, volvía a ascender junto a Dios, abriendo el camino para otras almas. Una vez desprendido de su prisión material (el cuerpo), el complejo alma-espíritu abandonaría el mundo sublunar, ascendiendo a través de las siete esferas planetarias hasta llegar a la Ogdóada (círculo de las estrellas fijas), donde se despojaría del alma y su espíritu se uniría con Dios.

Sin embargo, cada una de estas esferas o cielos planetarios que el alma tenía que atravesar estaba custodiada por un arconte. Éstos, también denominados principados o potestades, eran demonios intratables que actuaban como telónes o aduaneros encargados de comprobar los méritos de cada alma ascendente y verificar si estaba autorizada a continuar su viaje hasta el último cielo ${ }^{12}$. La mitología gnóstica disentía acerca del origen y condición de estas potencias, pero tendía a verlas en general, si no malignas, sí como hostiles al hombre. Había dos modelos: el planetario,

contrapartida divina del yo humano terrenal, pues en el mundo estaba sometida al destino, el nacimiento y la muerte. Cf. PIÑERO, A.; MONTSERRAT TORRENTS, J.; GARCÍA BAZÁN, F.: Textos gnósticos. Biblioteca de Nag Hammadi, I, Madrid, Trotta, 2000, pp. 33-37. He utilizado esta edición para todos los textos de Nag Hammadi (NHC), la citaré en adelante PIÑERO, A. (et. al.): Textos gnósticos..., indicando el volumen (I-III) y las páginas. Para las dificultades que entraña la tarea de definir al movimiento gnóstico v. KING, K. L.: What Is Gnosticism?, Cambridge/ London, The Belknap Press of Harvard University Press, 2003.

$10 \mathrm{El}$ vocablo gnosis significa «conocimiento». En el marco de la Historia de las religiones suele entenderse por «gnosis» el conocimiento de algo divino que trasciende la fe, una ciencia «absoluta» de la divinidad que se considera la verdad absoluta. Cf. PIÑERO, A. (et. al.): Textos gnósticos...(I), p. 34.

11 La doctrina de la psicanodia tenía un origen órfico y estaba vinculada a la creencia en la preexistencia de las almas, que unida a la demonología del helenismo tardío dio lugar a los mitos ascensionales del orfismo tardío, el judaísmo post-exílico, el hermetismo y la gnosis cristiana (PIÑERO, A. (et. al.): Textos gnósticos...(II), p. 130).

12 Archõn ( $\propto \varrho \chi \dot{\omega} v)$ : príncipe, gobernador. Pueden identificarse igualmente con los «Siete Rectores» del Hermetismo. Las figuras parecen derivar en última instancia del culto babilónico a los dioses planetarios, transformados en algún momento de su evolución en demonios malignos. Del s. I d. C. en adelante aparecen como rectores del destino, en conexión con las ideas astrológicas, y serán reconocidos sin distinción por paganos, gnósticos, judíos o cristianos, considerándoles todos como dotados de un poder maléfico (cf. DODDS, E. R.: Paganos y cristianos en una época de angustia, Madrid, Ediciones Cristiandad, pp. 33-35). 
que reconocía siete arcontes, y el zodiacal, que reconocía doce ${ }^{13}$. El modelo planetario defendía la existencia de siete esferas planetarias, gobernadas por el Demiurgo maligno, Yaldabaot, y otros seis ángeles o arcontes engendrados por él. Habían ayudado al Demiurgo a crear el mundo y por ello la humanidad les estaba sometida. Cada vez que un gnóstico lograba completar su ascensión hasta Dios, su alma escapaba al control de estas potencias, por lo que trataban de hacer todo lo posible para impedir que aquello sucediera. Orígenes, refutando a Celso, aporta la lista de los siete arcontes demonios que reconocían los Ofitas, cristianos gnósticos egipcios, que parecían concebirlos con apariencia animal: Yaldabaot, con forma de león; Ia, de toro; Sabaot, de dragón; Adoneo, de águila; Astafeo, de oso; Eloeo, de perro; y Horeo, de asno. Aseguraba el maestro alejandrino que para esta secta, estos ángeles arcónticos se situaban junto al cuerpo del moribundo, colocándose al otro lado siete ángeles de luz ${ }^{14}$. Listas similares de arcontes aparecen en otros textos egipcios como el Apócrifo de Juan o el tratado Sobre el Origen del Mundo ${ }^{15}$. Algunos grupos los veían de forma totalmente siniestra, como los Arcónticos, secta judeocristiana del s. IV d. C. presente en Palestina y Armenia, aunque con vínculos con Egipto, que creía que devoraban las almas gnósticas que podían capturar durante el ascenso ${ }^{16}$.

No obstante, muchas sectas gnósticas enseñaban a sus miembros determinadas palabras, frases o contraseñas, o les administraban ciertas unciones, bautismos o purificaciones, que permitían escapar de los arcontes

13 Existe además un modelo mixto, mezcla de ambos, que aparece por ejemplo en el Apócrifo de Juan (10: 25; 12: 25). Es posible que estos modelos zodiacales se deban a la subdivisión ulterior de uno de los círculos planetarios: el del Sol, lo que elevaría el número de potestades, como señalan A. Piñero y J. Monstserrat a propósito del modelo mixto. Cf. PIÑERO, A. (et. al.): Textos gnósticos...(I), pp. 67-68.

14 Orígenes da a entender que las contrapartidas angélicas de los arcontes, a saber: Miguel, Suriel, Rafael, Gabriel, Tautabaot, Erataot y Onoel-Tartaraot, también compartían, respectivamente, la forma de animal de cada uno de aquellos. Cf. ORÍGENES, Contra Celsum, 6: 24-32 (ed. BORRET, M.: Origène: Contre Celse (III: Livres V et VI), Sources Chrétiennes 147, Paris, Éditins du Cerf, 1969).

15 Cf. ApocJn (NHC II 1) 10: 25, 12: 25; OgM (NHC II 5) 101: 10, 104: 2 (PIÑERO, A. (et. al.): Textos gnósticos...(I), pp. 229-258 y 391-417). Un cuadro comparativo de las distintas listas puede verse en MONTSERRAT TORRENTS, J: Los gnósticos (II), BCG 60, Madrid, Gredos, p. 401.

16 Cf. EPIFANIO DE SALAMINA, Panarion, XL, 2: 7 (ed. y tr. in. de WILLIAMS, F.: The Panarion of Epiphanius of Salamis, Leiden /New York / Köln, Brill, 1998). En Hebrón fueron descubiertas sus estelas funerarias y en ellas aparece con frecuencia el motivo de la escalera cósmica de siete peldaños (scala cosmica), que representan las distintas etapas del ascenso del alma. Cf. DANIÉLOU, J.: «Para que se cumpla la escritura. El Cristianismo como secta judía» en TOYNBEE, A. (dir.): El crisol del Cristianismo, Barcelona, Editorial Labor, 1971, p. 269. 
y atravesar sus barreras ${ }^{17}$. Los discípulos de Marcos el Mago, por ejemplo, administraban a sus adeptos una unción especial de agua y aceite en el momento de su muerte, que hacía al alma invisible ante los arcontes, y además les enseñaban frases que confundían a estos principados y permitían evitarlos $^{18}$. Epifanio de Salamina citaba el perdido Evangelio de Felipe (distinto al hallado en Nag Hammadi) en el que Dios habría revelado a algunos gnósticos egipcios lo que tenían que responder a los poderes del aire para ascender hasta el Paraíso ${ }^{19}$. Orígenes también aportaba la lista de contraseñas ofitas para atravesar cada una de las puertas de los arcontes ${ }^{20}$. Los bautismos los encontramos en otros textos también procedentes de Egipto, como en El Pensamiento Trimorfo y sobre todo en Zostriano, cuyo protagonista homónimo abandona su figura (plásma) y asciende a las regiones celestes acompañado de un ángel, como Antonio, pero permaneciendo invisible a los arcontes. Allí recibe diversos bautismos purificadores y revelaciones místicas por parte de distintos seres celestes ${ }^{21}$.

En resumen, existe en el gnosticismo cristiano toda una tradición acerca de la ascensión del alma a los cielos, particularmente presente en la documentación de origen egipcio. Esta tradición puede relacionarse con la descripción que hace Atanasio de la ascensión del alma de Antonio en el capítulo 65 de la $V A$, y ayudar así a interpretar el ambiguo pasaje del obispo alejandrino.

\section{La RELECTURA DE LA PSICANODIA DE ANTONIO EN CLAVE GNÓSTICA}

La mayoría de los grupos gnósticos acabaron siendo considerados herejes por la Gran Iglesia, pero a la vez que una multitud de corrientes heterodoxas hubo también un gnosticismo cristiano ortodoxo. La corriente arranca de San Pablo_-al que Atanasio cita expresamente_-22 y fue especialmente importante en el cristianismo egipcio. En ella habría

17 Los órficos ya habían ideado tretas similares, como muestra, por ejemplo, la laminilla funeraria de oro de Petelia, de mediados del s. IV a. C., donde se registran frases que el alma debía decir al encontrarse con los guardianes ( $\varphi i \lambda \alpha x \varepsilon \varsigma$ ) del Más allá y llegar así hasta las venturosas moradas de los héroes. Cf. BERNABÉ, A; JÍMENEZ SAN CRISTOBAL, A. I.: Instrucciones para el más allá. Las laminillas órficas de oro, Madrid, Ediciones Clásicas, 2001, pp. $25-75$.

18 Cf. IRENEO DE LIÓN, Adversus Haereses, I, 21: 5 (ed. y tr. esp. en MONTSERRAT TORRENTS, J: Los gnósticos (I), BCG 59, Madrid, Gredos, 1983, pp. 77-250).

19 EPIFANIO DE SALAMINA, Panarion, XXVI, 13: 2.

20 Cf. ORÍGENES, Contra Celsum, 6: 31-32. Según el itinerario del relato de Orígenes (de la Ogdóada a la tierra), más que la ascensión del alma, parece describir el trayecto contrario, el descenso del Salvador. Cf. MONTSERRAT TORRENTS, J: Los gnósticos (II), BCG 60, Madrid, Gredos, nota 11, p. 255.

21 Cf. PensTr (NHC XIII) 45: 13-20, 48: 13-35; Zos (NHC VIII 1) passim (PIÑERO, A. (et. al.): Textos gnósticos...(I), pp. 325-347 y 281-304).

22 Vid. supra. nota 5. 
que incluir a pensadores de la talla de Clemente de Alejandría, Orígenes, Atanasio y el propio Antonio. Esta corriente defendía tradiciones similares al resto de gnósticos, como la noción del ascenso el alma y la existencia de los arcontes ${ }^{23}$, pero manteniéndose dentro de los límites de la ortodoxia. Su idea, en síntesis, era que la muerte de Cristo en la cruz en realidad fue una victoria que redimió a la humanidad de su cautiverio a manos de Satán y reabrió la vía para el ascenso ( $\dot{\alpha} \vee \delta \delta \varsigma s)$ de las almas hasta Dios, que aquel y sus esbirros habían conseguido obstruir; aunque iban a seguir amenazando el camino hasta su derrota definitiva al final de los tiempos. ${ }^{24}$ En el capítulo que aquí se analiza, Atanasio expresa su propia visión de esa tradición mítica.

Manteniendo aparte el asunto de cómo se produce la experiencia mística de Antonio ${ }^{25}$, parece evidente que el obispo está describiendo una psicanodia en su relato. Los tres aspectos fundamentales de la narración a dilucidar son: 1) la identidad de las potencias que intervienen, 2) la idea del juicio póstumo al alma humana, y 3 ) la concepción liminal de la conversión ascética, que establece un nuevo estatus en la persona que abraza la vida monástica.

En lo que se refiere a las potencias espirituales, lo lógico sería pensar que se trate de ángeles y demonios que desempeñan distintos papeles con respecto al alma y protagonizan en el pasaje una disputa por el control de la de Antonio, que al final resulta un juicio sobre la condición del asceta. Poco se puede decir de los ángeles, aparte de que éste es el único episodio de la $V A$ en el que ayudan al asceta en sus combates con los demonios. Sin embargo, no se puede precisar si su presencia se debe a la singularidad del caso o existe una categoría angélica destinada a escoltar a las almas para evitar posibles excesos por parte de las potencias malignas. Con respecto a los demonios, las luchas de Antonio contra ellos son un tema central en la obra. Desde las primeras tentaciones que sufre en su juventud, hasta los asaltos en su ancianidad, el asceta tendrá que hacerlos frente a lo largo de toda su vida monástica ${ }^{26}$. Antonio siempre sale victorioso, rechazando a sus malignos oponentes mediante la oración, el ayuno, los salmos, la Señal de la Cruz y la invocación del nombre de Cristo. Por eso sorprende especialmente su papel tan pasivo en el pasaje y es de suponer que Atanasio no esté haciendo referencia allí a un enfrentamiento convencional del asceta ni a los demonios habituales a los que aquél solía derrotar constantemente. A tenor de lo anteriormente explicado acerca de la psicanodia, es muy posible que tras la ambigüedad

23 Son los malignos cosmocrátores que cita Pablo en su Carta a los Efesios, lugartenientes de Satán, «príncipe del imperio del aire»; cf. Ef. 2: 2; 6: 12.

24 Cf. DANIÉLOU, J.: «Les démons de l'air...», pp. 136-143.

25 Realmente es secundario descubrir si Atanasio describe una visión, alucinación o un supuesto viaje extático del monje, toda vez que su intención es transmitir al lector lo ocurrido a Antonio, prefiguración de lo que el alma humana ha de esperar tras la muerte. 26 Cf. VA 5-6; 8-10; 11; 12-13; 40; 41; 50: 8 - 53. 
del obispo acerca de esos «seres terribles» se encuentren los arcontes gnósticos. Atanasio no dice nada de su aspecto, aparte de que son «amargos y terribles», pero en otros textos sí describirá con más detalle a los malignos demonios del aire. J. Daniélou apuntó que en sus comentarios al Salmo 67, el obispo afirmaba que: «la Caña ( $\dot{\alpha} \lambda \alpha \mu \circ \varsigma)$ es un lugar de Palestina que atraviesan los que suben a Jerusalén. Este lugar está lleno de leones agazapados en los pantanos que atacan a los que suben a Jerusalén. De la misma forma que estos leones asaltan a los que suben a Jerusalén, los

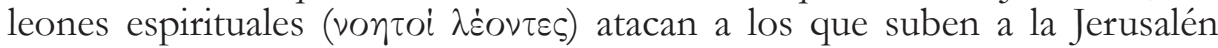
Celestial». El gnosticismo herético egipcio también utilizaba esta imagen, describiendo a menudo al Demiurgo maligno y sus arcontes como leones que pretenden devorar al alma en su camino al cielo ${ }^{27}$. En el Segundo Tratado del Gran Set, el Salvador gnóstico asegura estar «en las fauces de los leones» al saberse objetivo de los esfuerzos de los arcontes por acabar con él $^{28}$. Esta apariencia leónica es especialmente característica de Yaldabaoth. Algunos textos lo describen como una serpiente con cabeza de león ${ }^{29}$, otros, como un ser «andrógino y parecido a un león» ${ }^{30}$. Con forma de león también le concebían los Ofitas, considerándole en simpatía cósmica con el planeta Saturno ${ }^{31}$, de ahí tal vez el que en algunos casos se asemejase por sincretismo a las divinidades leontocéfalas del Mitraísmo ${ }^{32}$.

En segundo lugar, la noción de un juicio póstumo al alma humana (psicostasia), en el que se hace balance de su vida terrenal para ver si es digna de la eterna, es una idea presente en muchísimas religiones antiguas, comenzando por ejemplo el juicio de Osiris de la religión faraónica o el de Rashn en el Zoroastrismo ${ }^{33}$; aunque en el pasaje de Atanasio derivaría directamente de la función de aduaneros de los arcontes, que comprueban si el alma está autorizada a seguir su ascensión.

27 Cf. FILORAMO, G.: «Tra demoni e diavoli gnostici» en PRICOCO, S. (Ed.): Il Demonio e i suoi complici. Dottrine e credenze demonologiche nella Tarda Antichità, Messina, Rubbettino Editore, 1995, pp. 164-166.

28 Cf. TrGSt (NHC VII 2) 54: 20- 55: 15 (utilizo la edición de PIÑERO, A. (et. al.): Textos gnósticos...(III), pp. 173-184).

29 Cf. ApocJn 10: 14; esta descripción se corresponde también con la iconografía de la divinidad egipcia Chnoumis, presente en amuletos mágicos gnósticos. Cf. BONNER, C.: «Magical Amulets», The Harvard Theological Review, vol. 39, no 1 (1946), p. 54 (fig. 2), [versión online disponible en JSTOR: http://www.jstor.org/stable/1507999 (18/02/2011)]. 30 Cf. OgM 100: 1-9.

31 Cf. ORÍGENES, Contra Celsum, 6: 31.

32 Saturno era el dios griego del tiempo y en el Mitraísmo el Aion leontocéfalo representaba al Tiempo Eterno, también vinculado con el gnosticismo (cf. BOWMAN, A. K.: Egypt after the Pharaons 332 BC-AD 642, London, Bristish Museum Press, 1996, p. 175; en general sobre este tema v. JACKSON, H. M.: The Gnostic Leontomorphic Creator and the Platonic Tradition, Atlanta, Scholar Press, 1985, passim).

33 Sobre el juicio de Rashn, v. ELIADE, M.: Historia de las creencias y de las ideas religiosas, (IV), Madrid, Ediciones Cristiandad ,1980, pp. 374-377. 
Por último, quedaría por explicar por qué la conversión al ascetismo opera un cambio en Antonio que despoja a los arcontes de su autoridad para juzgarlo por sus acciones anteriores. La respuesta está en la consideración por parte de Atanasio de la vida monástica como un nuevo martirio ${ }^{34}$. El martirio era un combate contra los demonios que había sido ya equiparado por los cristianos con el bautismo y dotado de su mismo efecto redentor: era un "bautismo de sangre" que, como el sacramento, anulaba los pecados anteriores de quien lo recibía $a^{35}$. Por lo tanto, la disputa en los aires, además de probar la intachable conducta de Antonio, permite también a Atanasio reivindicarle como mártir sui generis y manifestar la idea de que abrazar la vida monástica supone aceptar un martirio espiritual equivalente a un nuevo bautismo.

En síntesis, Atanasio está describiendo en la visión del capítulo 65 de la VA una psicanodia del alma de Antonio hacia los cielos, guiada por ángeles, así como un juicio frustrado de ésta a manos de los arcontes, que tratan de impedir su trayecto, pero tienen que retirarse impotentes al comprobar que no hay pecado que reprocharle. El obispo prefiere reducir a estas potencias malignas a meras figuras anónimas, probablemente para, por un lado, distanciarse de las tradiciones heréticas en las que tenían tanto protagonismo y, por otro, evitar tal vez que con su preponderancia hicieran sombra al papel de Satán como antagonista central del alma cristiana durante su ascenso a los cielos.

\section{A MODO DE CONCLUSIÓN}

La descripción que hace Atanasio de la visión de Antonio que aquí se ha analizado constituye una clara adaptación por su parte de un mito gnóstico, reelaborado por el obispo para adecuarlo a su espiritualidad personal y a una formulación ortodoxa. Sin embargo, su objetivo no se reduciría a dotar de viabilidad discursiva a sus concepciones soteriológicas. Su intención en el pasaje también es refutar de forma implícita la postura gnóstica de utilizar contraseñas o frases para evitar a los «demonios del

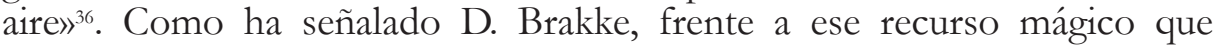

34 Atanasio cuenta en la VA que durante la persecución de Maximino Tracio (311 d. C.) Antonio había acudido a Alejandría para apoyar a los cristianos y dar testimonio de su fe, deseando un martirio que al final no sufrió. Frustrado, decidió regresar al desierto e intensificar sus ejercicios ascéticos, para combatir las batallas de la fe y vivir así en adelante un martirio interior (cf. VA 46-47).

35 Cf. TERTUliAnO, De Baptismo, 16 (ed. EVANS, E.: Tertullian's homily on Baptism, London, SPCK, 1964).

36 Otro indicador del choque doctrinal de Atanasio y los grupos gnósticos heréticos de Egipto puede ser el hecho de que los textos de la Biblioteca de Nag Hammadi se entierran en esta época, posiblemente para evitar su destrucción. A. Piñero, J. Monserrat y F. García Bazán han recordado que Atanasio publicó en el 367 su 39. ${ }^{a}$ Carta festal, en la que establecía los escritos del Nuevo Testamento que debían considerarse divinamente 
garantiza la salvación, independientemente de la responsabilidad moral de la persona, Atanasio plantea que la manera de inmunizarse frente a los peligros del $\dot{\alpha} \nu 0 \delta$ os es comportarse de forma moralmente diligente ${ }^{37}$. Si una persona no peca y se comporta correctamente, viviendo según los valores cristianos, preferiblemente los ascéticos, Satán y los «demonios del aire» no tendrán prueba alguna contra su alma. De nada sirven las tretas gnósticas; ni siquiera un taumaturgo sin parangón como Antonio puede hacer nada contra ellos en este punto. Pero se podría decir todavía más. Con su postura, Atanasio extendía la salvación a todos los cristianos, alejándose del elitismo gnóstico que la restringía a una minoría poseedora de conocimientos especiales. De esta forma, en la $V A$, planteada nominalmente para los ascetas occidentales, pero dirigida en realidad al conjunto de los fieles, Atanasio enseñaba a los cristianos corrientes que Cristo reabrió el camino para que las almas llegasen hasta Dios, pero recordándoles a la vez que si querían alcanzar ese destino dichoso, debían ganárselo con el esfuerzo de vivir rectamente su vida.

\footnotetext{
inspirados, preocupado precisamente por la difusión en Egipto de libros heréticos que eran presentados como revelados. Plantean estos autores, además, que tal vez dichos textos (quizás algunos de los hallados en Nag Hammadi) fueran fruto de una religiosidad «laica» de grupos gnósticos, opuesta a la de los monjes. Cf. PIÑERO, A. (et. al.): Textos gnósticos... (I), pp. 31-32.

37 Cf. BRAKKE, D.: Athanasius and Asceticism, Baltimore / London, Johns Hopkins University Press, 1995, p. 219.
} 
